\title{
Application of Geographic Information Systems to Identify the Oversummering Regions of Blumeria graminis f. sp. tritici in China
}

\author{
Boning Li, State Key Laboratory for Biology of Plant Disease and Insect Pests, Institute of Plant Protection, Chinese Academy of \\ Agricultural Sciences, Beijing 100193, China; Xueren Cao, State Key Laboratory for Biology of Plant Disease and Insect Pests, \\ Institute of Plant Protection, Chinese Academy of Agricultural Sciences, and Key Laboratory of Integrated Pest Management on \\ Tropical Crops, Ministry of Agriculture, Environment and Plant Protection Institute, Chinese Academy of Tropical Agricultural \\ Sciences, Haikou 571001, China; Lin Chen, Ningxia Entry-Exit Inspection and Quarantine Bureau, Yinchuan 750002, China; Yilin \\ Zhou and Xiayu Duan, State Key Laboratory for Biology of Plant Disease and Insect Pests, Institute of Plant Protection, Chinese \\ Academy of Agricultural Sciences; Yong Luo, Department of Plant Pathology, China Agricultural University, Beijing 100193; Bruce \\ D. L. Fitt, University of Hertfordshire, Hatfield, Hertfordshire AL10 9AB, UK; Xiangming Xu, East Malling Research, New Road, \\ East Malling, Kent ME19 6BJ, UK; Yuli Song, Institute of Plant Protection, Henan Academy of Agricultural Sciences, Zhengzhou \\ 450002, China; Baotong Wang, College of Plant Protection, Northwest Agriculture and Forestry University, Yangling 712100, China; \\ and Shiqin Cao, Institute of Plant Protection, Gansu Academy of Agricultural Sciences, Lanzhou 730070, China
}

\begin{abstract}
Li, B., Cao, X., Chen, L., Zhou, Y., Duan, X., Luo, Y., Fitt, B. D. L., Xu, X., Song, Y., Wang, B., and Cao, S. 2013. Application of geographic information systems to identify the oversummering regions of Blumeria graminis f. sp. tritici in China. Plant Dis. 97:1168-1174.

Blumeria graminis f. sp. tritici, the pathogen that causes wheat powdery mildew, can oversummer as mycelia or conidia on leaves of volunteer wheat plants in cool mountainous areas in China. In this study, the regions in China where B. graminis f. sp. tritici can oversummer were identified on the basis of the probability that temperature remains below a critical temperature that is lethal to $B$. graminis f. $\mathrm{sp}$. tritici. Two methods, one describing the relationship between the average temperature $\left(20\right.$ to $\left.26^{\circ} \mathrm{C}\right)$ in a given continuous 10-day period and wheat powdery mildew severity, the other describing the relationship between the average temperature $\left(26\right.$ to $\left.33^{\circ} \mathrm{C}\right)$ and the number of lethal days on powdery mildew development, were used to calculate the oversummering probability using weather data for 743 sites across China. Spatial interpolation based on the ordinary kriging method was conducted for the regions without observation. Oversummering proba-

bility values were similar for most locations estimated between the two methods. The B. graminis f. sp. tritici oversummering regions in China were identified to be in mountainous or high-elevation areas, including most regions of Yunnan, west and central areas of Guizhou, south and northwest Sichuan, south and east Gansu, south Ningxia, north and west Shaanxi, central-north Shanxi, west Henan and Hubei, and some regions in Qinghai, Tibet, and Xinjiang. When the oversummering sites from this study were compared with observed survey data for some of these sites, about $90 \%$ of sites where B. graminis f. sp. tritici oversummering was observed had been found suitable by both methods. The coincidence frequency and the area under the receiver operating characteristic curve for model 2 were higher, albeit only slightly, than those for model 1 . Thus, both methods may be used to assist in disease management and further investigation on pathogen oversummering.
\end{abstract}

Wheat powdery mildew, caused by Blumeria graminis f. sp. trit$i c i$, is one of the most destructive foliar diseases of wheat worldwide, especially in areas with maritime or semi-continental climates (1). In China, wheat powdery mildew epidemics have become severe since the late 1970s. The most destructive epidemics occurred in 1990 and 1991, causing yield losses up to 1.44 and 0.77 million tons, respectively (17).

The optimal temperatures for development of powdery mildew were 15 to $22^{\circ} \mathrm{C}$ and disease development is reduced when temperature is $>25^{\circ} \mathrm{C}(21)$. The critical period in the life cycle of $B$. graminis f. sp. tritici is oversummering (18). The pathogen cannot survive over summer in most wheat-growing regions in China because it is exposed to an average temperature $>25^{\circ} \mathrm{C}$ for more than 10 consecutive days. This oversummering period includes the period of wheat ripening, harvesting, and seed sowing in autumn for next season. Generally, B. graminis f. sp. tritici can survive over summer as mycelium or conidia on leaves of volunteer wheat plants in the cool mountainous areas of China (37). The infected

Corresponding author: Y. Zhou, E-mail: ylzhou @ippcaas.cn

B. Li and X. Cao contributed equally to this work.

Accepted for publication 10 February 2013.

http://dx.doi.org/10.1094/PDIS-10-12-0957-RE

(c) 2013 The American Phytopathological Society volunteer plants may produce conidia that serve as primary inoculum for epidemics in autumn crops. It was reported that the pathogen can also survive hot, dry summers as cleistothecia $(7,13)$. However, most cleistothecia of B. graminis f. sp. tritici could not oversummer to directly infect autumn-sown wheat in China $(4,9,35,38)$. Thus, mycelium or conidia on leaves of volunteer wheat plants in cool areas could be the main phase of $B$. graminis f. sp. tritici oversummering in China. Therefore, it is important to determine the pathogen oversummering regions on volunteer wheat plants in China for disease prediction and management.

Regions in China where B. graminis f. sp. tritici oversummers on volunteer wheat crops have been reported from survey information $(5,15,31,34,39)$. However, such disease scouting is time consuming and labor intensive, and it is practically impossible to obtain sufficient data for all the regions in China where the pathogen may occur.

Geographic Information Systems (GIS) are computer systems able to assemble, store, manipulate, and display data referenced by geographic coordinates (27). GIS can be adapted to any size of operation and data can be incorporated at various spatial scales from a single field to an agricultural region (24). GIS has been used in spatial analysis of plant diseases $(12,25,33)$. Hijmans et al. (11) used two GIS-linked potato late blight (LB) forecast models to develop an LB-specific agroecological zonation, based on estimates of the number of fungicide sprays needed for effective disease management. The oversummering regions for Puccinia striiformis in China were also defined with a GIS-based method (20). 
The objectives of this study were to identify the oversummering regions of $B$. graminis $\mathrm{f}$. sp. tritici in China. Two models were developed to estimate the probability that $B$. graminis f. sp. tritici can oversummer at a particular location. Both models were built on the basis that high temperatures reduce the survival and development of $B$. graminis f. sp. tritici and used GIS to estimate the oversummering probability over a region using kriging. The oversummering regions predicted by the two models were compared with those from surveys for 138 sites.

\section{Materials and Methods}

Data and data sources. Weather data. Daily average temperature in July and August at 743 weather stations in China (Fig. 1) from 1951 to 2006 were obtained from the National Meteorological Center of China.

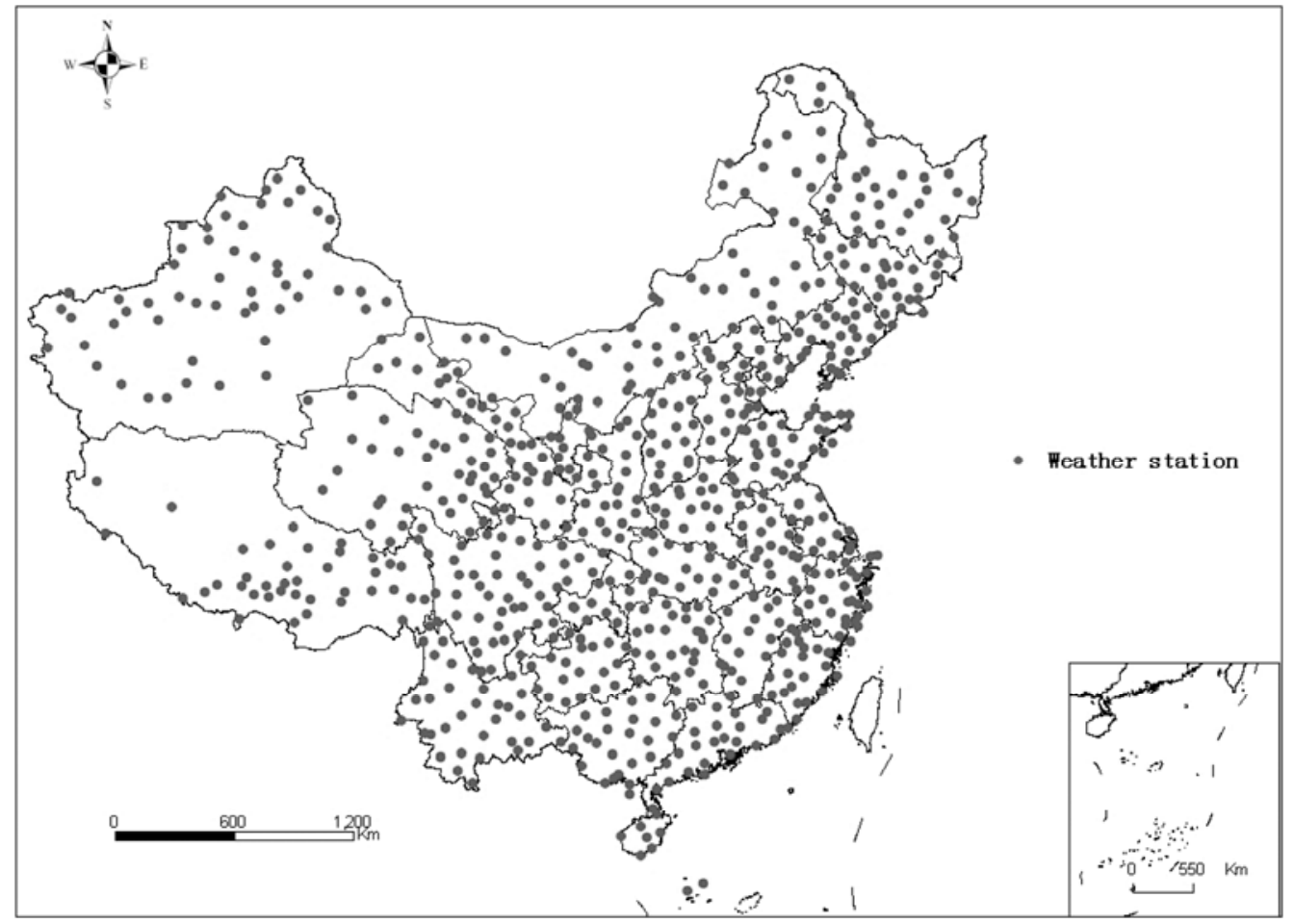

Fig. 1. Geographical location of weather stations throughout China used in the study.

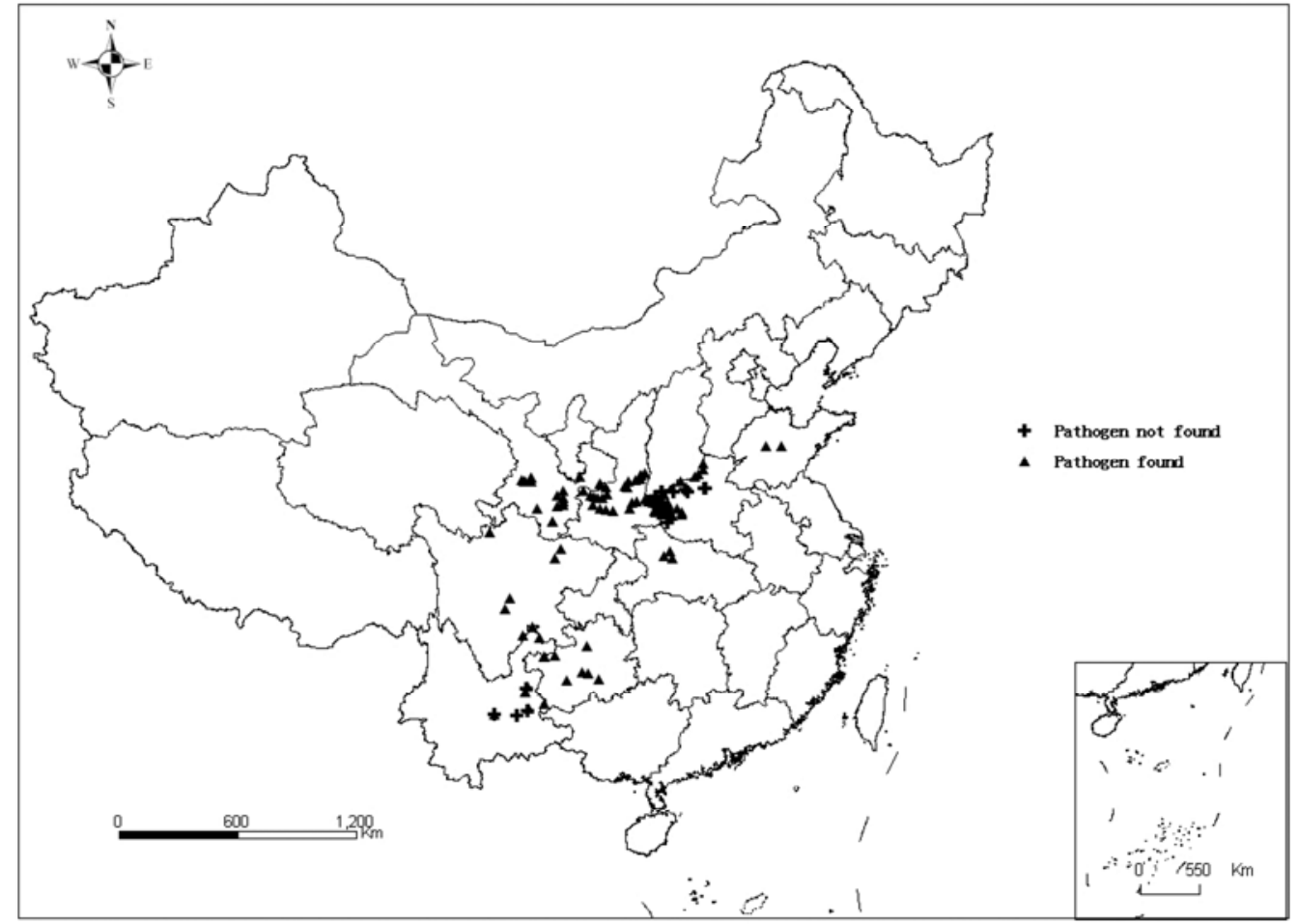

Fig. 2. Geographical location of the oversummering survey sites used in this study. Symbols indicate positions of the individual survey sites. Black triangle $(\mathbf{A})$ indicates pathogen found on volunteer plants at the surveys; black cross (+) indicates pathogen not found on volunteer plants at the surveys. 
Spatial data. A map of China showing province information $(1: 4,000,000)$ was downloaded from the National Fundamental Geographic Information System of China (http://nfgis.nsdi.gov.cn). A map of wheat-growing regions in China was also scanned from the Chinese Agricultural Atlas (28) and digitalized by using ESRI's ArcGIS 8.3.

Oversummering of wheat powdery mildew. The survey data for B. graminis f. sp. tritici oversummering were collected from two sources: oversummering surveys by the authors in 2004, 2005, and 2007 (unpublished data) and oversummering survey data $(5,15,19,31,34,39)$. In 2004 and 2005, seven and six counties, respectively, were surveyed in Henan Province. Nine, one, and five counties were surveyed in Gansu, Guizhou, and Yunnan Province, respectively, in 2007. The position of each site was identified using the global positioning system (GPS) GPSmap 60CSx (Garmin Ltd., Taipei, Taiwan). In total, 138 survey sites were used in this study (Fig. 2).

Models used for defining $B$. graminis f. sp. tritici oversummering regions. $B$. graminis f. sp. tritici oversummering is mainly affected by host availability and environmental conditions, especially temperature $(18,39)$. Generally, there is a period of 7 to 10 days from infection of leaves by $B$. graminis f. sp. tritici to full development of symptoms (32). In this study, the average daily temperatures in July and August coinciding with the oversummering period for $B$. graminis f. sp. tritici were used. The probability that $B$. graminis f. sp. tritici can oversummer at a given site was estimated using the following two models.

Model 1. This model was based on results from a controlledenvironment study, describing the relationship between the average temperature $\left(20\right.$ to $\left.26^{\circ} \mathrm{C}\right)(\mathrm{T})$ in a given continuous 10-day period and wheat powdery mildew severity (percent leaf area with mildew) $(y)$, as $y=76.60-3 \mathrm{~T}$ (14). This model predicts that visual symptoms will not develop if the average temperature in a given continuous 10 -day period is greater than $25.5^{\circ} \mathrm{C}$. If the average daily temperature in any continuous 10-day period at a given location is $\geq 25.5^{\circ} \mathrm{C}$ in July and August in a given year, the pathogen is then assumed not to be able to oversummer in that year at this particular location. The maximum of the average temperature in a continuous 10-day period at location $i$ in year $j$ $\left(T_{i, j}\right)$ during July and August was defined as $T_{i, j}=\max \left(t_{i, j}\right)$, where $t_{i, j}$ is the average temperature in a given continuous 10-day period at location $i$ and year $j$ during July and August. The number of years that the pathogen cannot oversummer at location $i\left(Y_{i}\right)$ was calculated as:

$$
Y_{i}=\sum_{j=1}^{m} P V_{i, j}
$$

where $P V_{i, j}=0$ when $T_{i, j}<25.5^{\circ} \mathrm{C}$ and $P V_{i, j}=1$ when $T_{i, j} \geq 25.5^{\circ} \mathrm{C}$, and $m$ is the total number of years with weather data for location $i$. The probability of $B$. graminis f. sp. tritici oversummering at location $i\left(F_{i}\right)$ was calculated as $F_{i}=\left(1-Y_{i} / m\right) \times 100 \%$. $F_{i}$ for location $i$ was calculated with a computer program written by the authors (Visual Basic) following the principle that, if the average daily temperature in any continuous 10 -day period was $\geq 25.5^{\circ} \mathrm{C}$ in year $j$, then $Y_{i}$ would be assigned as 1 and calculation of the $Y_{i}$ value for the next year would continue. Otherwise, if this temperature was $<25.5^{\circ} \mathrm{C}$ in year $j$, then $Y_{i}$ would be assigned as 0 . The annual probabilities that $B$. graminis f. sp. tritici could oversummer at 743 sites were calculated.

Table 1. Semivariogram models and spatial distribution parameters of the probability provided by both models

\begin{tabular}{lccccccc}
\hline Model & Semivariogram model & Nugget & Sill & Range & $\mathbf{r}^{\mathbf{a}}$ & RMSE $^{\mathbf{b}}$ & Number of lags $^{-}$ \\
\hline 1 & Spherical & 0.0427 & 0.1976 & 20.66 & 0.2161 & 0.2433 & 12 \\
2 & Spherical & 0.0477 & 0.1940 & 22.69 & 0.2458 & 0.2510 & 10 \\
\hline
\end{tabular}

${ }^{\mathrm{a}}$ Random variation $=$ nugget $/$ sill.

${ }^{\mathrm{b}} \mathrm{RMSE}=$ the root mean square error.

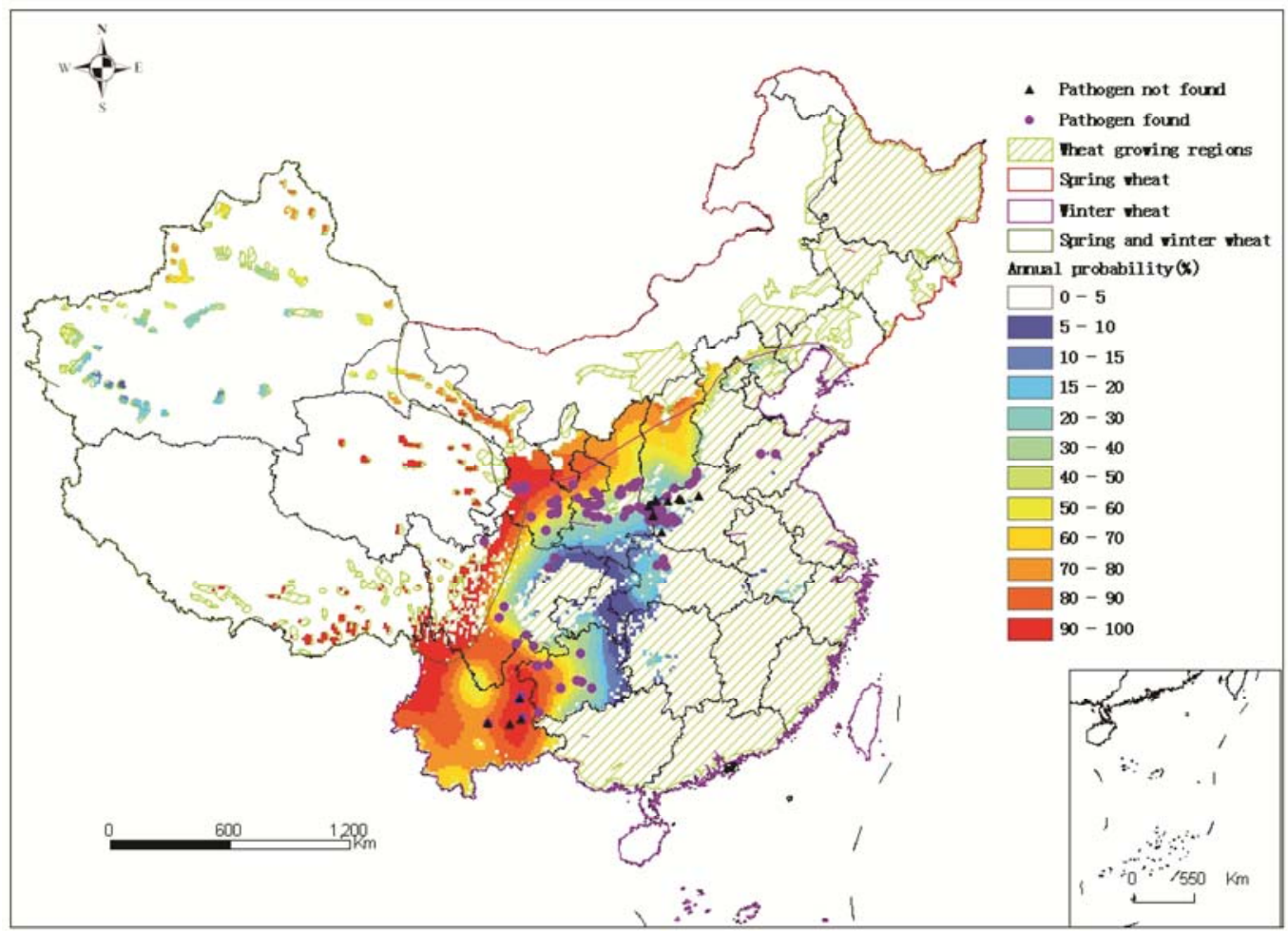

Fig. 3. Oversummering regions for Blumeria graminis $\mathrm{f}$. $\mathrm{sp}$. tritici based on the annual probability (\%) that average daily temperature for continuous 10 -day periods is $<25.5^{\circ} \mathrm{C}$ (model 1) combined with wheat-growing regions in a geographic information system. 
Model 2. This model was also based on a controlled-environment study (14), describing the relationship between the average temperatures $\left(26\right.$ to $\left.33^{\circ} \mathrm{C}\right)(T)$ and the number of lethal days $(D)$ on powdery mildew development at the corresponding average tem- peratures as $D=[21,900 \exp (-0.3035 T)]$, where $T$ is daily average temperature $>26^{\circ} \mathrm{C}$. Because 7 to 10 days are needed from infection of leaves to full development of powdery mildew symptoms under favorable conditions, the accumulated lethal effect $\left(C_{i, j}\right)$ of

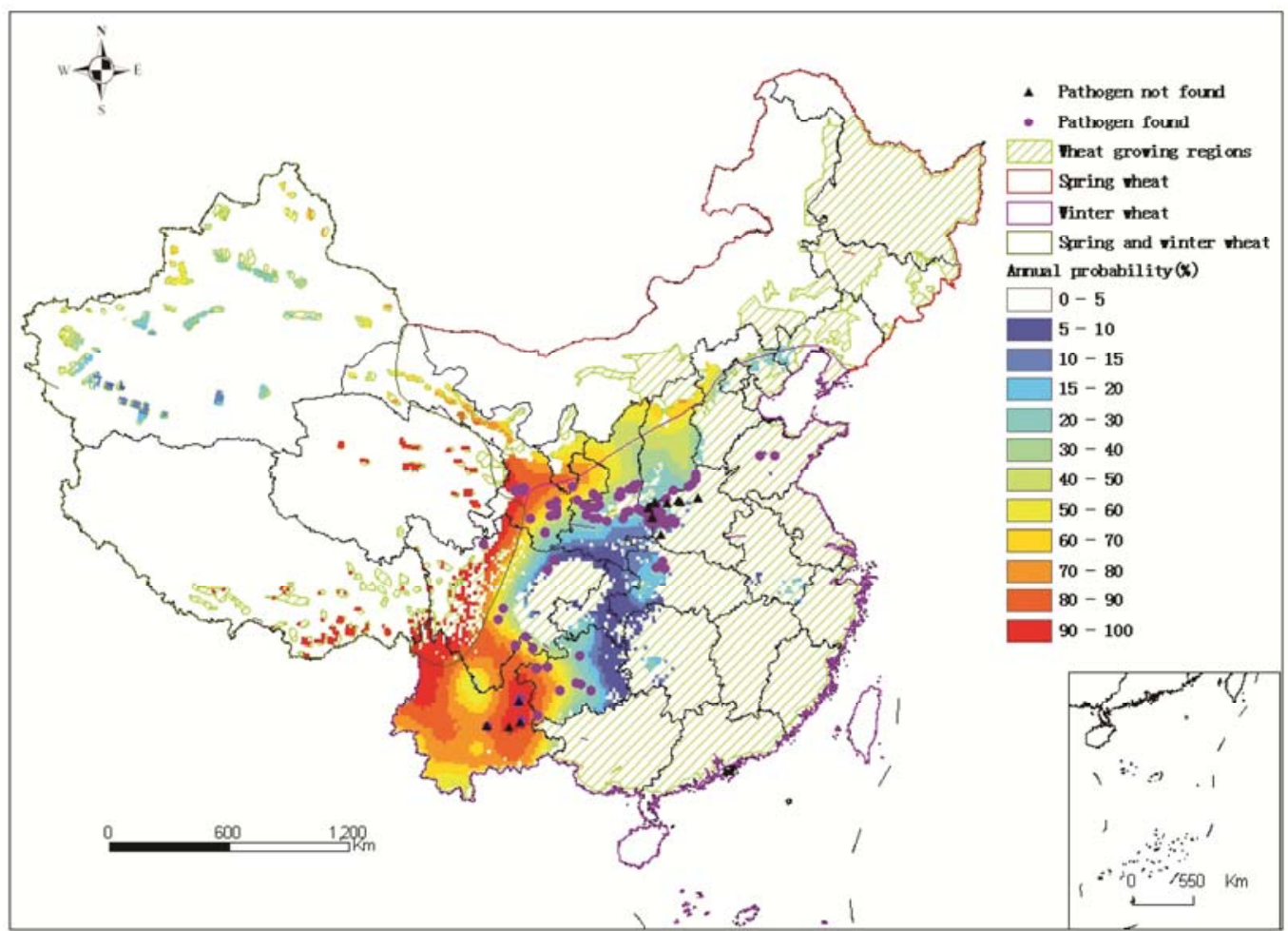

Fig. 4. Oversummering regions for Blumeria graminis f. sp. tritici based on the annual probability (\%) that the effect of accumulated lethal daily temperature $\left(>26^{\circ} \mathrm{C}\right)$ on disease development in continuous 10-day periods $<1$ (model 2) combined with wheat-growing regions in a geographic information system.

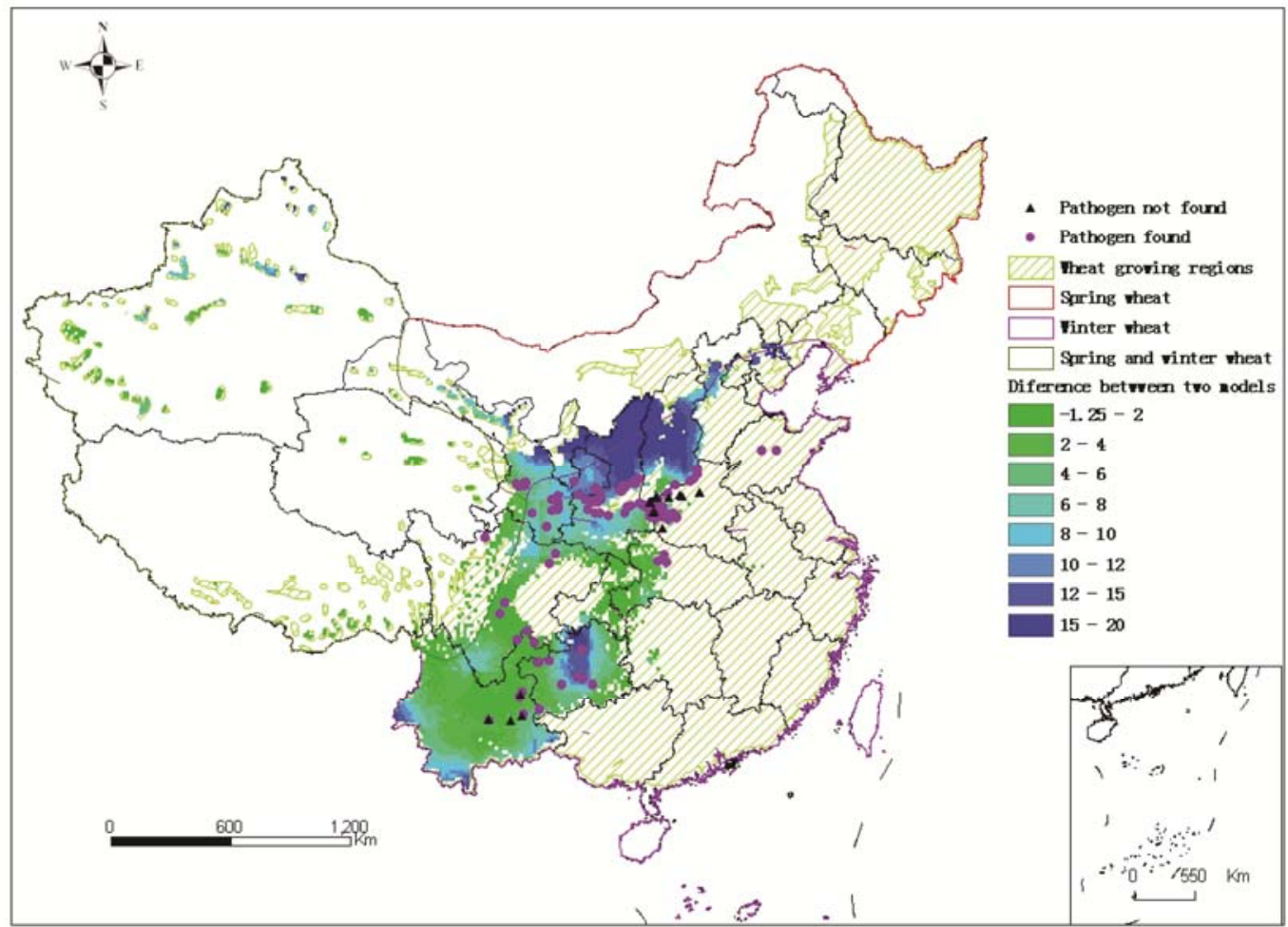

Fig. 5. Differences between the two models in calculated annual probabilities (\%) of oversummering regions combined with wheat growing regions in a geographic information system. 
daily temperature on disease development at location $i$ in year $j$ within a given continuous 10-day period was estimated as

$$
C_{i, j}=\sum_{d=1}^{10}\left(1 / D_{i, j, d}\right)
$$

Thus, if $C_{i, j} \geq 1$, the pathogen was assumed not able to oversummer at location $i$ in year $j$. The model describes more quantitative lethal effects of high temperatures on the disease development than model 1. For example, at daily average temperature of 26 and $29^{\circ} \mathrm{C}$, it takes 8 and 4 days, respectively, for $C_{i, j}>1.0$. As for model 1 , the number of years that the pathogen cannot oversummer at location $i\left(Y_{i}\right)$ was calculated as

$$
Y_{i}=\sum_{j=1}^{m} P V_{i, j}
$$

where $P V_{i, j}=0$ when $C_{i, j}<1, P V_{i, j}=1$ when $C_{i, j} \geq 1$, and $m$ is the total number of years with weather data at location $i$. Here, $C_{i, j}$ is the maximum value for any given continuous 10-day period at location $i$ in year $j$. The probability of $B$. graminis f. sp. tritici oversummering at location $i\left(F_{i}\right)$ was then calculated as $F_{i}=\left(1-Y_{i} / m\right) \times 100 \%$.

All calculations were done using a computer program (Visual Basic) similar to model 1 for 743 sites.

Oversummering zonation using GIS. Both models were used to calculate the probability that $B$. graminis $\mathrm{f}$. sp. tritici could oversummer at a given site for 743 sites where temperature data were available for years from 1951 to 2006.

To identify $B$. graminis f. sp. tritici oversummering areas in China on the basis of the estimated annual probabilities of $B$. graminis f. sp. tritici oversummering at the 743 sites, the ordinary kriging method was applied (2). Before kriging, the spatial structure of each probability of pathogen oversummering provided by the two models was defined from semivariogram parameters: nugget, sill (or total semivariance), and range. Nugget is the variance at distance zero and represents the experimental error (small-scale heterogeneity). Sill is the semivariance value at which the semivariogram reaches the upper bound after its initial increase. Range is the value (x-axis) at which the variable becomes spatially independent; that is, the lag-distance at which the semivariogram flattens. The ratio of nugget to sill quantifies the importance of the random component and provides a quantitative estimation of the spatial dependence. Values of the nugget to sill ratio $<0.25,0.25$ to 0.75 , or $>0.75$ indicated strong, moderate, or weak spatial autocorrelation, respectively (3). The ratio of nugget to sill was calculated to assess the appropriateness of spatial interpolation (16). If the ratio was less than 0.25 , kriging interpolating was considered reliable.

Spatial variation has been characterized using different models (spherical, circular, and so on) fitting the semivariograms. Choice of the best fitting model was based on the lowest root mean square error. Cross-validation and ordinary kriging have been applied to extrapolate the values of areas without temperature data. To generate the variograms, kriging interpolation, and surface maps, the software ArcGis 8.3 Geostatistical Analysis and its extension Spatial Analyst were used.

Validation of the predicted $B$. graminis f. sp. tritici oversummering regions. Receiver operating characteristic (ROC) curve analysis (36) was used to evaluate the performance of the two models in predicting the probability of $B$. graminis $\mathrm{f}$. sp. tritici oversummering at a total of 138 sites where $B$. graminis f. sp. trit$i c i$ oversummering was surveyed. Among the 138 sites surveyed, B. graminis f. sp. tritici found to have produced disease symptoms on volunteer plants at 121 sites.

The sensitivity (the proportion of data sets where disease can oversummer that were classified correctly) and specificity (the percentage of data sets where disease could not oversummer that were classified correctly) of each model was determined by calculating the proportion of data sets that were classified correctly in cross-validation, assuming a probability of group membership above a probability threshold, or "cut-point." A cut-point is a point on an ROC curve used to dichotomize predictions of a con- tinuous variable into categories, with each cut-point corresponding to a predictive threshold for a model. To construct empirical ROC curves, model sensitivity (referred to as true positive proportion) was plotted against 1 - specificity (referred to as false positive proportion) by allowing the cut-point to vary over the range of its possible values (6). The area under the ROC curve (AUROC) was calculated to compare models (6).

For each model, the cut-point where the overall error rate was smallest was determined by selecting the cut-point with the highest value of Youden's index, $J$, which identifies the point on the ROC curve at the greatest geometric distance from the line representing a noninformative predictor (23). Youden's index is commonly used as a measure of overall prediction effectiveness and is calculated by $J=$ sensitivity + specificity $-1(23)$.

The coincidence frequency rate $(\%)$ between the model predictions and observation data for the 121 sites were then calculated as coincidence frequency $(\%)=$ [number of oversummering sites (predicted by model)]/[number of oversummering sites (powdery mildew observed)].

\section{Results}

Identification of $B$. graminis f. sp. tritici oversummering regions. Key parameters of semivariograms for the probability of $B$. graminis f. sp. tritici oversummering provided by both models are provided in Table 1. The optimal theoretical models of the probability provided by both models were of the spherical type model.

Geostatistical analysis results showed that the probability values of $B$. graminis f. sp. tritici oversummering given by both models had strong spatial autocorrelations (with nugget to sill ratio $=0.216$ and 0.246 , for models 1 and 2, respectively). Therefore, it was considered justifiable to use the kriging method to interpolate these probability values (Figs. 3 and 4).

The probability values of $B$. graminis f. sp. tritici oversummering were $>50 \%$ in most regions of Yunnan, west Guizhou, south and northwest Sichuan, south and east Gansu, south Ningxia, north and west Shaanxi, central-north Shanxi, and some regions in Qinghai and Tibet provinces. Thus, these regions may be classified as areas where there is a high risk for $B$. graminis $\mathrm{f}$. sp. tritici oversummering. Oversummering probability values of 15 to $50 \%$ were obtained for the central Shaanxi, west Henan, northwest Hubei, central Guizhou, central-south and south Shanxi, and some regions in Xinjiang and south Anhui provinces. Thus, these regions may be regarded as areas of moderate risk for $B$. graminis f. sp. tritici oversummering. Oversummering probability values of 5 to $15 \%$ were predicted for east Guizhou, southeast Chongqing, southwest and northwest Hubei, south Shaanxi, and marginal areas of the Sichuan Basin. Thus, these areas may be classified as areas at low risk for $B$. graminis f. sp. tritici oversummering. All other regions had predicted probability values of $<5 \%$ and may be considered as not suitable for B. graminis $\mathrm{f}$. $\mathrm{sp}$. tritici oversummering.

Comparison of model predictions. Predictions given by the two models were compared. The differences between the two models in estimated values for probability of oversummering were all $<24 \%$ (Fig. 5). For most of the predictions, the differences were $<5 \%$. Differences $>10 \%$ were all restricted to the regions in the central Shanxi, north Shaanxi, east Ningxia, and the central area of Guizhou.

The AUROC curves for model 1 and model 2 were 0.8192 and 0.8214 , respectively (Fig. 6). Youden's index identified the optimal cut-points as $15 \%$ for both models. At this threshold, the sensitivity and specificity of the models in cross validation were 94.9 and $62.2 \%$ for model 1, respectively; the corresponding values for model 2 were 94.9 and $64.9 \%$, respectively. Thus, a threshold of $15 \%$ indicated whether B. graminis f. sp. tritici can oversummer at a given site.

Validation of the model predictions. Most of the 121 sites where B. graminis f. sp. tritici was observed to have produced powdery mildew on volunteer seedlings were also classified as oversummering sites by both models: 108 of 121 sites for model 1 and 
110 of 121 sites for model 2 (Table 2). The coincidence frequency for model 1 and model 2 was 89.3 and $90.9 \%$, respectively.

\section{Discussion}

Temperature in summer is the key factor that determines whether $B$. graminis f. sp. tritici can oversummer at a given region (18). In this study, the suitability of each region for $B$. graminis f. sp. tritici oversummering was estimated by two models on the basis of the lethal effects of high temperatures on $B$. graminis f. sp. tritici development. According to the ROC curve analysis, regions with probability of $>15 \%$ as estimated by the two models were considered to be the $B$. graminis f. sp. tritici oversummering regions. Both model identified that the B. graminis f. sp. tritici oversummering regions in China were all located in the mountainous or high-elevation areas, including central-west and southwest China, because the average daily temperature is relatively cool (always $<26^{\circ} \mathrm{C}$ ) in summer in these regions, coinciding with the conditions of $B$. graminis $\mathrm{f}$. $\mathrm{sp}$. tritici growth (1). All regions in China where $B$. graminis f. sp. tritici was previously reported to oversummer on volunteer wheat plants $(5,15,31,34,38)$ were located in oversummering regions identified by the two models.

The regions identified by this study as suitable for B. graminis $\mathrm{f}$. sp. tritici oversummering were consistent between the two models, except for those in the central Shanxi, north Shaanxi, east Ningxia, and central Guizhou. The reason for this difference may be that model 2 considered the lethal effects of high temperatures on the B. graminis f. sp. tritici development in a more quantitative manner than model 1 . For this reason, predictions given by model 2 would be expected to be more accurate than those by model 1 . The coinci-

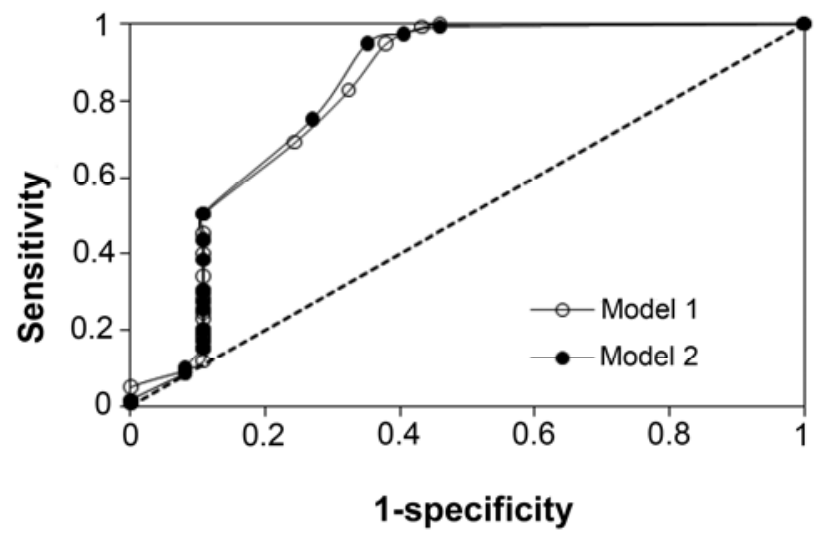

Fig. 6. Receiver operating characteristic plots with curves for the two models in calculated annual probabilities (\%) of oversummering regions. The dashed line represents the line of no discrimination for a predictive system that does predict infection better than by chance. dence frequency and AUROC for model 2 were higher, albeit only slightly, than those for model 1.

Daily average temperatures from 743 weather stations from 1961 to 2006 in China were used in our study. The validation study also demonstrated that coincidence frequencies reached $90 \%$ when comparing the predicted data with observed data. There were several sites that were found to have infected volunteer seedlings during the surveys; however, these sites were not predicted to be suitable for $B$. graminis f. sp. tritici oversummering. The estimated probability was 5 to $15 \%$ for these sites. Thus, it may be important to monitor summer temperatures at these regions because the pathogen may be able to oversummer when the temperatures are unusually low in July and August.

It has been reported that $B$. graminis primary inoculum may mainly originate from cleistothecia in autumn-sown cereal areas with hot and dry summers $(7,13)$. Moreover, the probability of direct infection of autumn-sown cereals by ascospores has also been suggested to be low $(22,29)$. Discharge of ascospores from cleistothecia on wheat straw can take place when moisture is high. High temperature and high humidity can shorten the longevity of cleistothecia of $B$. graminis f. sp. tritici (10). It is unlikely that cleistothecia may retain the ability to discharge ascospores until autumn in China because of frequent rains caused by monsoons and high temperatures in summer (8). It was demonstrated that cleistothecia of B. graminis f. sp. tritici cannot survive the summer to infect autumn seedlings in China $(4,9,35,38)$. Because volunteer wheat plants in oversummering areas serve as the main hosts for the pathogen, eliminating volunteer wheat seedlings through ploughing and other means could significantly reduce the level of the initial inoculum.

Global climate has been gradually changing since pre-industrial times. Strong evidence of global warming over the past five decades is supported by the continuous measurements from 412 meteorological stations, which showed that annual temperature has increased by $1.2^{\circ} \mathrm{C}$ in China since 1960 (26). Differences in the sensitivity of $B$. graminis f. sp. tritici isolates collected from different provinces or districts to temperature in China in recent years and the frequency distribution of $B$. graminis f. sp. tritici isolates with different sensitivity to temperature did not fit a normal distribution, which indicated that global climate change may have influence on the evolution of $B$. graminis f. sp. tritici (30). Therefore, the effects of global climate change and the evolution of $B$. graminis $\mathrm{f}$. sp. tritici responses to temperature should be taken into account when assessing the suitability of particular sites for $B$. graminis $\mathrm{f}$. sp. tritici oversummering. In addition, the elevation in different regions should also be considered together with the digital elevation model to improve prediction accuracy.

\section{Acknowledgments}

This work was financially supported by National Key Basic Research Program of China (2010CB951503, 2013CB127700), National Key Technology

Table 2. Number of sites that Blumeria graminis f. sp. tritici can oversummer by survey and number of these sites that can oversummer using the two models used in this study in each province ${ }^{\mathrm{a}}$

\begin{tabular}{|c|c|c|c|c|c|c|c|}
\hline \multirow[b]{2}{*}{ Province } & \multirow[b]{2}{*}{$\begin{array}{c}\text { Number of oversummering } \\
\text { survey sites }\end{array}$} & \multicolumn{2}{|c|}{$\begin{array}{c}\text { Powdery mildew on } \\
\text { volunteer seedlings }\end{array}$} & \multicolumn{4}{|c|}{ Predicted oversummering sites } \\
\hline & & $\begin{array}{l}\text { Number of sites } \\
\text { with }\end{array}$ & $\begin{array}{c}\text { Number of sites } \\
\text { without }\end{array}$ & $\begin{array}{l}\text { Number using } \\
\text { model } 1\end{array}$ & $\begin{array}{c}\text { Coincidence } \\
\text { frequency }(\%)\end{array}$ & $\begin{array}{c}\text { Number using } \\
\text { model } 1\end{array}$ & $\begin{array}{c}\text { Coincidence } \\
\text { frequency }(\%)\end{array}$ \\
\hline Henan & 64 & 51 & 13 & 45 & 88 & 47 & 92 \\
\hline Shaanxi & 25 & 25 & 0 & 22 & 88 & 22 & 88 \\
\hline Gansu & 17 & 17 & 0 & 17 & 100 & 17 & 100 \\
\hline Yunnan & 8 & 4 & 4 & 4 & 100 & 4 & 100 \\
\hline Guizhou & 11 & 11 & 0 & 11 & 100 & 11 & 100 \\
\hline Sichuan & 8 & 8 & 0 & 6 & 75 & 6 & 75 \\
\hline Hubei & 3 & 3 & 0 & 3 & 100 & 3 & 100 \\
\hline Shangdong & 2 & 2 & 0 & 0 & 0 & 0 & 0 \\
\hline Total & 138 & 121 & 17 & 108 & 89 & 110 & 91 \\
\hline
\end{tabular}

${ }^{a}$ Coincidence frequency was calculated for the two models in each province: coincidence frequency $(\%)=$ [number of oversummering sites (predicted by model)]/[number of oversummering sites (powdery mildew observed)]. 
R\&D Programs of China (2012BAD19 B04), and Special Fund for Agro-scientific Research in the Public Interest (201303016). We thank J. S. West, Rothamsted Research, Harpenden, UK for his constructive comments to improve the quality of this manuscript prior to submission.

\section{Literature Cited}

1. Bennett, F. G. A. 1984. Resistance to powdery mildew in wheat: a review of its use in agriculture and breeding programmes. Plant Pathol. 33:279-300.

2. Burgess, T. M., and Webster, R. 1980. Optimal interpolation and isarithmic mapping of soil properties: I. The semivariogram and punctual kriging. J. Soil Sci. 31:315-331.

3. Cambardella, C. A., Moorman, A. T., Novak, J. M., Parkin, T. B., Karlen, D. L., Turco, R. F., and Konopka, A. E. 1994. Field-scale heterogeneity of soil properties in central Iowa soils. Soil Sci. Soc. Am. J. 58:1501-1511.

4. Cao, X. R., Zhou, Y. L., Duan, X. Y., Song, Y. L., He, W. L., Wang, B. T., and Li, Q. 2010. The contribution of chasmothesia of Blumeria graminis $\mathrm{f}$. sp. tritici to its infection cycle. Plant Prot. 36:145-148.

5. Duan S. K., and Liu, C. H. 1994. Preliminary report on the over-summering and spread of wheat powdery mildew in Guanzhong area of Shaanxi Province. Acta Phytopathol. Sin. 24:121-122.

6. Fawcett, T. 2006. An introduction to ROC analysis. Pattern Recogn. Lett. 27:861-874.

7. Felsenstein, F. G. 1996. Effects of sexual reproduction on population dynamics of wheat and barley powdery mildew in Europe. Pages 91-96 in: Integrated Control of Cereal Mildews and Rusts: Towards Coordination of Research across Europe. Official Publications of the European Communities, Luxembourg.

8. Guo, Z. H., Liu, X. M. X., Xiao, W. F., Wang, J. L., and Meng, C. 2007. Regionalization and integrated assessment of climate resource in China based on GIS. Resour. Sci. 29:2-9.

9. He, S. C., Lin, D. F., Pang, C. C., Wang, D. J., and Zhang, K. Q. 1984. Research on the primary infection source of Erysiphe graminis f. sp. tritici in Guizhou. Acta Phytophylacica Sin.11:214-216.

10. He, S. C., Lin, D. F., Wang, X. L., and Yang, C. F. 1985. On biological specialty of sexual reproduction of wheat powdery mildew (Erysiphe graminis DC. f. sp. tritici Marchal). Acta Phytopathol. Sin. 5:109-114.

11. Hijmans, R. J., Forbes, G. A., and Walker, T. S. 2000. Estimating the global severity of potato late blight with GIS-linked disease forecast models. Plant Pathol. 49:697-705.

12. Jaime-Garcia, R., and Cotty, P. J. 2006. Spatial distribution of Aspergillus flavus and its toxigenic strains on commercial cottonseed from south Texas and its relationship to aflatoxin contamination. Plant Pathol. 55:358-366.

13. Koltin, Y., and Kenneth, R. 1970. The role of the sexual stage in the oversummering of Erysiphe graminis DC. f. sp. hordei Marchal under semi-arid conditions. Ann. Appl. Biol. 65:263-268.

14. Li, B. N., Zhou, Y. L., and Duan, X. Y. 2008. Effects of temperature on wheat powdery mildew. Plant Prot. 34:22-25.

15. Li, H. 1987. The source of initial inoculum of wheat powdery mildew in Sichuan basin. J. Southwest Agric. Univ. 9:159-165.

16. Li, H. B., and Reynolds, J. F. 1995. On definition and quantification of heterogeneity. Oikos 73:280-284.

17. Liu, W. C., and Shao, Z. R. 1994. Epidemiology, occurrence and analysis of wheat powdery mildew in recent years. Plant Prot. Tech. Ext. 6:17-20.

18. Liu, X. K. 1989. Advance on wheat powdery mildew in China. Res. Agric. Hus. Inform. 8:1-10

19. Liu, X. K., Zhou, Y. L., and Liang, G. D. 1990. Investigation on the over- summering of asexual generation of Erysiphe graminis f. sp. tritici in Nanyang. Plant Prot. 1:33

20. Ma, Z. H., Shi, S. D., Jiang, Y. Y., and Zhao, Z. H. 2005. Climate-based regional classification for oversummering of Puccinia striiformis in China with GIS. Acta Phytopathol. Sin. 34:455-462.

21. Mathre, D. E. 1982. Compendium of Barley Diseases. American Phytopathological Society, St. Paul, MN.

22. Menzies, J. G., and MacNeill, B. H. 1989. The sexual state of Erysiphe graminis f. sp. tritici on winter wheat in southern Ontario. Can. J. Plant Pathol. 11:279-283.

23. Metz, C. E. 1978. Basic principles of ROC analysis. Nucl. Med. 8:283-298.

24. Nelson, M. R., Thomas, V. O., Ramon, J. G., and Athar, N. 1999. Applications of geographic information systems and geostatistics in plant disease epidemiology and management. Plant Dis. 83:308-319.

25. Orum, T. V., Bigelow, D. M., Nelson, M. R., Howell, D. R., and Cotty, P. J. 1997. Spatial and temporal patterns of Aspergillus flavus strain composition and propagule density in Yuma County, Arizona, soils. Plant Dis. 81:911-916.

26. Piao, S., Giais, P., Huang, Y., Shen, Z., Peng, S., Li, J., Zhou, L., Liu, H., Ma, Y., Ding, Y., Friedlingstein, P., Liu, C., Tan, K., Ye, Y., Zhang, T., and Fang, J. 2010. The impacts of climate change on water resources and agriculture in China. Nature 467:43-51.

27. Star, J., and Estes, J. 1990. Geographic Information Systems: An Introduction. Prentice Hall, Englewood Cliffs, NJ.

28. The Compilation Committee of National Atlas. 1989. National Agricultural Atlas of the People's Republic of China. China SinoMaps Press, Beijing.

29. Turner, D. M. 1956. Studies on cereal mildew in Britain. Trans. Br. Mycol. Soc. 39:495-506

30. Wan, Q., Ding, K. J., Duan, X. Y., and Zhou, Y. L. 2010. Sensitivity of population of Blumeria graminis f. sp. tritici isolates to temperature in 2008. Acta Phytopathol. Sin. 40:106-109.

31. Wang, S. T. 1984. Study on the inoculum of primary infection of wheat powdery mildew. Hubei Agric. Sci. 11:19-23.

32. Wang, Z. L., Li, L. H., He, Z. H., Duan, X. Y., Zhou, Y. L., Chen, X. M., Lillemo, M., Singh, R. P., Wang, H., and Xia, X. C. 2005. Seedling and adult plant resistance to powdery mildew in Chinese bread wheat cultivars and lines. Plant Dis. 89:457-463.

33. Wu, B. M., van Bruggen, A. H. C., Subbarao, K. V., and Pennings, G. G. H. 2001. Spatial analysis of lettuce downy mildew using geostatistics and geographic information systems. Phytopathology 91:134-142.

34. Wu, M. Z., Yan, S. H., and Hu, G. Q. 1984. Oversummering and overwintering of wheat powdery mildew and study on its biological characteristics. Guizhou Agric. Sci. 3:31-36.

35. Yang, D. B., Liu, X. K., Song, F. X., and Sun, Q. 1996. Studies on the primary infection source of wheat powdery mildew in Beijing. Acta Phytophylacica Sin. 23:300-304.

36. Yuen, J., and Hughes, G. 2002. Bayesian analysis of plant disease prediction. Plant Pathol. 51:407-412.

37. Zeng, X. W., Luo, Y., Zheng, Y. M., Duan, X. Y., and Zhou, Y. L. 2010. Detection of latent infection of wheat leaves caused by Blumeria graminis $\mathrm{f}$. sp. tritici using nested PCR. J. Phytopathol. 158:227-235.

38. Zhang, Z. D., and Li, Z. Q. 1991. The laws of occurrence and development of powdery mildew of wheat in Tianshui area. J. Northwest Sci.-Tech. Univ. Agric. For. (Suppl.) 19:81-86.

39. Zhang, Z. D., Li, Z. Q., and Zong, Z. F. 1993. The laws of occurrence of powdery mildew of wheat in central area of Shaanxi Province. J. Northwest Sci.-Tech. Univ. Agric. For. 21:25-31. 